\title{
Preschool children in out-of-hours primary care - a questionnaire-based cross- sectional study of factors related to the medical relevance of health problems
}

\author{
Grete Moth $^{1,2^{*}}$ (D) Linda Huibers ${ }^{1,2}$, Astrid Ovesen ${ }^{1,2}$, Morten Bondo Christensen ${ }^{1,2}$ and Peter Vedsted ${ }^{1,2}$
}

\begin{abstract}
Background: Out-of-hours primary care $(\mathrm{OOH}-\mathrm{PC})$ is intended to provide medical care services for health problems that cannot wait until normal office hours. Children under five years of age represent about $19 \%$ of all OOH-PC contacts in Denmark, and the frequency of calls assessed as severe by health professionals is markedly lower for children than for other age groups. Several studies have questioned the appropriateness of the parents' use of $\mathrm{OOH}-\mathrm{PC}$. We aimed to identify factors associated with calls from parents of pre-school children concerning perceived non-severe health problems that were ranked by the triaging GPs as more appropriate for GP office hours (defined as 'medically irrelevant').
\end{abstract}

Methods: We used data from a cross-sectional study performed in the Central Denmark Region for a 1-year period during 2010-2011. GPs in the OOH-PC assessed random contacts, and a questionnaire was subsequently sent to registered patients. Associations between different factors and the medical irrelevance of contacts were estimated with a generalised linear model to calculate the prevalence ratio (PR).

Results: Among all included 522 telephone consultations and 1226 face-to-face consultations, we identified 71 (13.6\%) telephone consultations and 95 (7.8\%) face-to-face consultations that were both assessed as non-severe by the parents and more appropriate for GP office hours by the GPs. For telephone consultations, contacts at other times than 4-8 pm on weekdays were statistically significantly associated with medical irrelevance. Additionally, symptoms of longer duration than $24 \mathrm{~h}$ were statistically significantly associated medical irrelevance.

Conclusions: A large part of the calls to the Danish OOH-PC concern children. The results indicate that some of these calls are made for other than strictly medical reasons. To achieve more effective use of available resources, it might seem relevant to aim at directing more contacts directly to daytime care. However, future studies to enhance our knowledge on parents' motivation and behaviour would be recommendable.

Keywords: Denmark, General practice, Out-of-hours, Appropriateness, Severity, Reason for encounter

\footnotetext{
* Correspondence: moth@ph.au.dk

${ }^{1}$ Research Unit for General Practice, Department of Public Health, Aarhus University, Bartholins Alle 2, 8000 Aarhus, Denmark

${ }^{2}$ Section for General Medical Practice, Department of Public Health, Aarhus University, Bartholins Alle 2, 8000 Aarhus, Denmark
} 


\section{Background}

Out-of-hours primary care (OOH-PC) in Denmark is organised in large cooperatives consisting of general practitioners (GPs) as in many other western countries [1-3]. The OOH-PC is intended for urgent medical problems that cannot wait until normal office hours. Nevertheless, several studies have shown that $50-77 \%$ of calls are assessed as inappropriate or non-urgent by health professionals and could have been directed to a GP in daytime or managed as self-care [4-6]. Consequently, the workload at the $\mathrm{OOH}-\mathrm{PC}$ is high, and the demands are significant [7].

Studies across countries have shown that young children account for $5-19 \%$ of the $\mathrm{OOH}-\mathrm{PC}$ contacts [8-10]. The proportion of calls assessed as severe is lower for children than for other age group [11]. According to a Danish study, $46 \%$ of parents who contacted OOH-PC did not consider their child's condition to be truly serious or urgent [12]. Furthermore, a Dutch study showed that about half of patients thought that $\mathrm{OOH}-\mathrm{PC}$ was intended for all health-related problems, including non-urgent issues [4].

Therefore, it is relevant to analyse the medical relevance of contacts concerning children as this could provide an understanding of the $\mathrm{OOH}-\mathrm{PC}$ use for this group. Our aim was to examine contacts for 0-5-yearold children at the $\mathrm{OOH}-\mathrm{PC}$ regarding reasons for encounter (RFE), symptom duration, time of contact, urbanisation and severity of health problem as assessed by parents and the OOH-PC GP on duty. Furthermore, for contacts considered as non-severe by parents, we explored factors that were associated with being assessed as more suitable for own GP within office hours by the triaging GPs in order to gain knowledge on how to identify the potentially avoidable contacts.

\section{Methods \\ Design}

We conducted a cross-sectional study based on secondary analyses of data from a survey on RFE and disease patterns in the Danish OOH-PC (the LV-KOS cohort study) in the Central Denmark Region [8]. During the 1-year study period (1 June 2010 - 31 May 2011), data on $\mathrm{OOH}-\mathrm{PC}$ contacts were generated on the basis of GP registrations of contacts and patient questionnaires. A total of 385 of all 700 GPs in the region participated in the survey at least once $(55.0 \%)$, and a GP collected data for $96 \%$ of all telephone calls in each shift. In total, 21,457 random contacts were registered: 7810 telephone calls, 6973 face-to-face consultations and 6674 home visits.

\section{Setting}

The OOH-PC provides care for the 1.25 million inhabitants in the region and registers 670,000 calls annually.
In the Danish OOH-PC services, patients must call the $\mathrm{OOH}-\mathrm{PC}$ call centres, which are managed by fully licensed GPs. Nearly $60 \%$ of calls are terminated as telephone consultations (medical advice or direct admission to the hospital) and $40 \%$ as telephone referrals (referral to subsequent face-to-face consultation (clinic visit or home visit)).

\section{Data collection}

At the start of each shift at the OOH-PC, one GP from each type of consultation (phone, clinic, home visit) could sign up electronically in the study as they logged on to the computerized patient administration system. Participating GPs received an electronic pop-up questionnaire after terminating every tenth telephone call, every third clinic consultation and every home visit. The questions focused on a range of characteristics of the contact, such as the RFE (stated in text), and duration of symptoms. Moreover, a question concerned whether the patient ought to have attended own GP within office hours (either before or after the OOH-PC contact) instead of contacting the OOH-PC.

Two to three days after the registered OOH-PC contact, the patients received a postal questionnaire, including a question about their assessment of the severity of the health problem prompting a call. Patients registered with more than one contact in the study received only one questionnaire (after the first contact). Moreover, contacting patients with permanent address outside the region did not receive a questionnaire. Data on age, date, time and type of contact were collected from the electronic patient administration system.

\section{Data management}

Focusing on children aged 0-5 years and their parents' decision to call the $\mathrm{OOH}-\mathrm{PC}$, we categorised the children into two age groups: $<3$ years and $3-5$ years. Contacts were categorised into two groups: telephone consultations and face-to-face consultations (clinic visits, home visits).

RFEs stated in text in the patient records were obtained and manually coded using the International Classification of Primary Care, 2nd Edition (ICPC-2) [13] by a specifically trained medical student, who was supervised by the researchers. The four most frequently applied RFE diagnoses were identified, and all additional RFEs (143 in total) formed a group of "other RFEs". Duration of symptoms was categorised into four groups: $<5 \mathrm{~h}, 5-12 \mathrm{~h},>12-24 \mathrm{~h}$ and $>24 \mathrm{~h}$. Based on the contact pattern in $\mathrm{OOH}-\mathrm{PC}$, which showed a peak during the first opening hours, the time of contact was categorised into three groups: weekday evenings (4-8 pm), weekday nights (8 pm-8 am), and weekends and holidays. Geographical location was based on the postcode of the 
patient's home address and categorised according to number of citizens in the postcode area: rural $(\leq 5000)$ and urban (>5000).

The patient-assessed severity was dichotomised into "potentially severe" (combining "Severe and lifethreatening" and "Severe but not life-threatening") and "not severe" (combining "Not severe, but I needed to talk to a doctor" and "Not ill, but I had some questions").

\section{Analysis}

We compared respondents and non-respondents among the parents on the basis of relevant variables available in this study (age groups, type of contact, symptom duration, geographical location and GP-assessed medical relevance for the $\mathrm{OOH}-\mathrm{PC}$ ). Baseline characteristics of the included contacts were presented for telephone consultations and face-to-face consultations together with the proportion of contacts that the participating $\mathrm{OOH}$ PC GPs considered to be more appropriate for the daytime GP. Next, we identified the subgroup of calls that the OOH-PC GPs considered more appropriate for the daytime GP and that were also assessed as non-severe by the parents. This subgroup is henceforth referred to as "medically irrelevant contacts" in this paper. In a generalised linear model (GLM), we examined, for each consultation type, the association between being categorised in this subgroup and age, duration of symptoms, time of contact and geographical location; these associations were presented as estimates of prevalence ratios (PR) and 95\% confidence intervals (95\% CI). In this analysis, answers of "don't know" to assessment of severity were excluded as were RFEs with too few observations. Analyses were performed by Stata 14 statistical software.

\section{Results}

During the study period, 3857 contacts regarding children aged 0-5 years were registered. Of these, 292 were excluded, primarily because they were registered with more than one contact. Of the remaining 2923 contacts, completed patient questionnaires were returned for 1748 contacts (59.8\%), which were included in the analyses (522 telephone consultations and 1226 face-to-face consultations). Respondents and nonrespondents did not differ significantly, except for the GP-assessment of appropriateness. The GPs found that $18 \%$ of the contacts from respondents compared with $24 \%$ from non-respondents could have been more appropriately targeted to the daytime GP than to the OOH-PC $(P<0.001)$ (Table 1$)$.

More contacts concerned children aged 0-2 years than children aged 3-5 years; this was found for both types of consultations (Table 2). The duration of symptoms was most often under five hours for telephone consultations (31.8\%) and over $24 \mathrm{~h}$ for face-to-face consultations (31.6\%). In total, $60.7 \%$ of telephone consultations and $40.6 \%$ of face-to-face consultations were assessed as non-severe by the parents.

According to the GPs, $17.6 \%$ of telephone consultations and $18.4 \%$ of face-to-face contacts were found to be more appropriate for the daytime GP (Table 2). Contacts at 4-8 p.m. on weekdays $(24.6 \%$ of telephone consultations and $22.7 \%$ of face-to-face consultations) and contacts with symptom duration $>24 \mathrm{~h}(26.9 \%$ and

Table 1 Comparison of characteristics between respondents and non-respondents

\begin{tabular}{|c|c|c|c|c|}
\hline & & $\begin{array}{l}\text { Respondents } \\
(n=)(\%)\end{array}$ & $\begin{array}{l}\text { Non-respondents } \\
(n=)(\%)\end{array}$ & $P$-value \\
\hline \multirow[t]{2}{*}{ Age } & $0-2$ years & 1216 (69.6) & $829(70.5)$ & 0.568 \\
\hline & $3-5$ years & $532(30.4)$ & $346(29.5)$ & \\
\hline \multirow[t]{2}{*}{ Type of contact } & Telephone consultation & $522(29.9)$ & $357(30.4)$ & 0.764 \\
\hline & Face-to-face consultation & $1.226(70.1)$ & $818(69.6)$ & \\
\hline \multirow[t]{5}{*}{ Symptom duration } & $<5 \mathrm{~h}$ & $439(25.1)$ & $278(23.7)$ & 0.069 \\
\hline & $5-12 h$ & $396(22.7)$ & $271(23.1)$ & \\
\hline & $12-24 h$ & $376(21.5)$ & $233(19.8)$ & \\
\hline & $>24 h$ & $517(29.6)$ & $365(31.1)$ & \\
\hline & Missing & $20(1.1)$ & $28(2.4)$ & \\
\hline \multirow[t]{3}{*}{ Geographical location } & Urban & $727(41.6)$ & $524(44.6)$ & 0.220 \\
\hline & Rural (<5000 inhab. Per zip code) & $92352.8)$ & $582(49.5)$ & \\
\hline & Missing & $98(5.6)$ & $69(5.9)$ & \\
\hline \multirow[t]{3}{*}{ More appropriate for the daytime GP according to the OOH-PC GP } & No & $1.309(74.9)$ & $803(68.3)$ & $<0.001$ \\
\hline & Yes & $317(18.1)$ & $284(24.1)$ & \\
\hline & Don't know & $122(7.0)$ & $88(7.5)$ & \\
\hline
\end{tabular}


Table 2 Characteristics of OOH-PC contacts for preschool children and proportions considered by GPs to be more appropriately targeted to the daytime GP $(N=1748)$

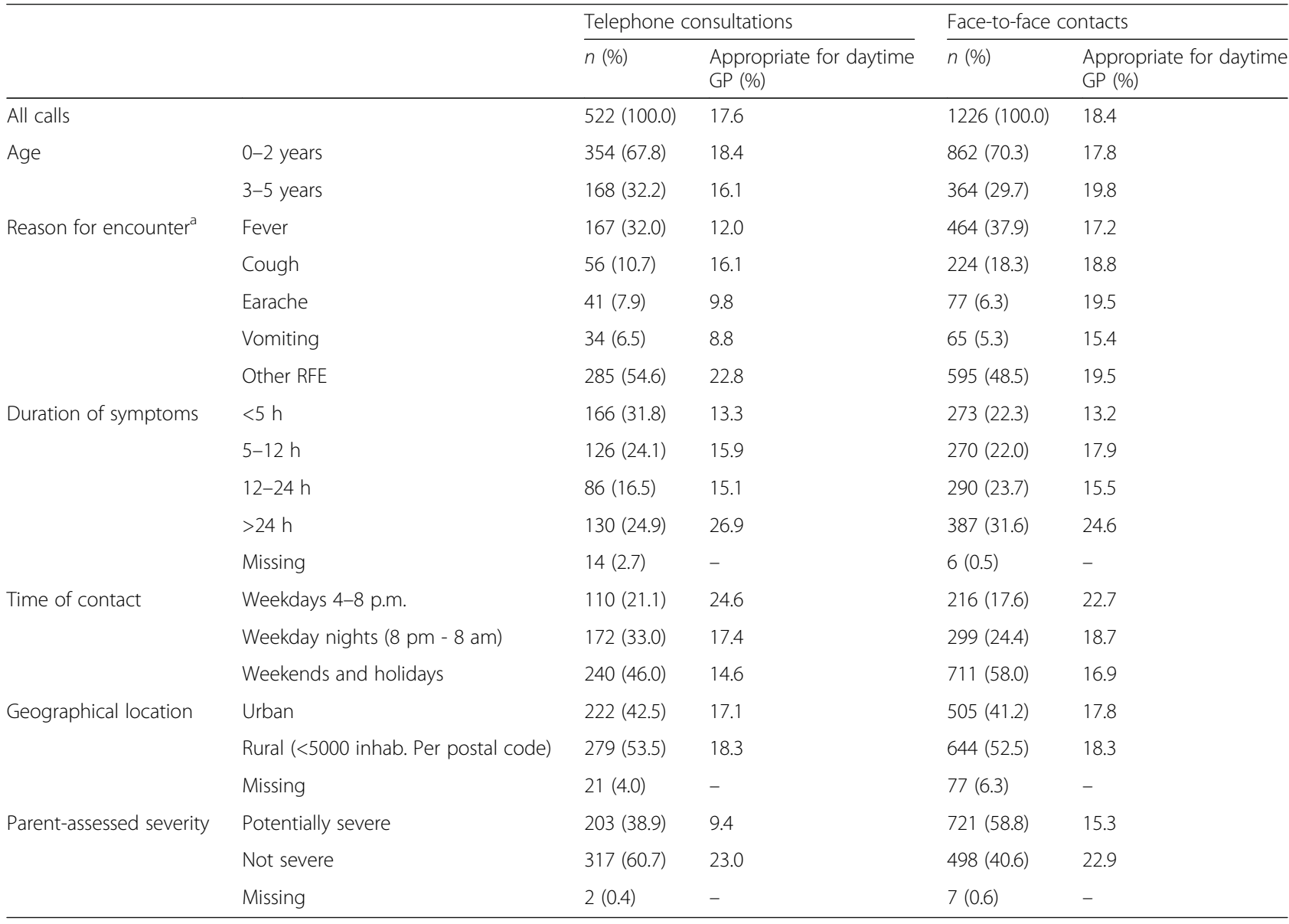

${ }^{a}$ The five most frequent RFEs; numbers add up to more than the total as several RFEs were stated for some cases

$24.6 \%$, respectively) were most often assessed to be more relevant for daytime care than $\mathrm{OOH}-\mathrm{PC}$.

Table 3 depicts the parent-assessed problem severity in relation to the GP-assessed appropriateness of contacts for OOH-PC. For telephone consultations that were considered more appropriate for daytime care by the
GPs, $79.4 \%$ of the consultations were assessed as nonsevere by the parents. For face-to-face consultations, the corresponding figure was $50.7 \%$. It should be noted that the agreement between GP-assessed appropriateness of contact and parent-assessed severity of health problem generally was low.

Table 3 Distribution of parent-assessed severity and GP-assessed appropriateness of OOH-PC contacts

\begin{tabular}{|c|c|c|c|c|c|}
\hline & \multirow[b]{2}{*}{ Parent-assessed severity } & \multicolumn{4}{|c|}{ More appropriately targeted to the daytime GP } \\
\hline & & $\begin{array}{l}\text { Yes } \\
(n=)(\%)\end{array}$ & $\begin{array}{l}\text { No } \\
(n=)(\%)\end{array}$ & $\begin{array}{l}\text { Don't know } \\
(n=)(\%)\end{array}$ & All \\
\hline \multirow[t]{4}{*}{ Telephone consultations } & Not severe & $73(79.4)$ & $221(56.5)$ & $23(59.0)$ & $317(60.7)$ \\
\hline & Potentially severe & 19 (20.6) & $169(43.2)$ & $15(38.5)$ & $203(38.9)$ \\
\hline & Don't know & 0 & $1(0.3)$ & $1(2.5)$ & $2(0.4)$ \\
\hline & All & $92(100)$ & $391(100)$ & $39(100)$ & $522(100)$ \\
\hline \multirow[t]{4}{*}{ Face-to-face consultations } & Not severe & $114(50.7)$ & $346(37.7)$ & $68(45.8)$ & $498(40.6)$ \\
\hline & Potentially severe & $110(48.9)$ & $566(61.7)$ & $45(54.2)$ & $721(58.8)$ \\
\hline & Don't know & $1(0.44)$ & $6(0.6)$ & 0 & $7(0.6)$ \\
\hline & All & $225(100)$ & $918(100)$ & $83(100)$ & $1.226(100)$ \\
\hline
\end{tabular}


Table 4 Factors associated with medically irrelevant contacts (problems considered non-severe by parents and more appropriate for the daytime GP by triaging GPS)

\begin{tabular}{|c|c|c|c|c|c|c|}
\hline \multirow[t]{2}{*}{ Characteristics } & \multicolumn{3}{|c|}{$\begin{array}{l}\text { Telephone consultations } \\
\left(n=71^{\mathrm{a}}\right)\end{array}$} & \multicolumn{3}{|c|}{$\begin{array}{l}\text { Face-to-face contacts } \\
\left(n=95^{\mathrm{a}}\right)\end{array}$} \\
\hline & Prevalence & $\begin{array}{l}\text { Adj. prevalence ratio }{ }^{b} \\
(95 \% \mathrm{Cl})\end{array}$ & $p$-value & Prevalence & $\begin{array}{l}\text { Adj. prevalence ratio } \\
(95 \% \mathrm{Cl})\end{array}$ & $p$-value \\
\hline \multicolumn{7}{|l|}{ Age } \\
\hline$<3$ years & 0.15 & 1 (reference) & & 0.09 & 1 (reference) & \\
\hline $3-5$ years & 0.13 & $0.99(0.61-1.62)$ & 0.982 & 0.11 & $1.41(0.96-2.06)$ & 0.077 \\
\hline \multicolumn{7}{|l|}{ Duration of symptoms } \\
\hline$<5 \mathrm{~h}$ & 0.13 & 1 (reference) & & 0.06 & 1 (reference) & \\
\hline $5-12 \mathrm{~h}$ & 0.13 & $0.94(0.50-1.75)$ & 0.834 & 0.10 & $1.86(0.95-3.62)$ & 0.069 \\
\hline$>12-24 \mathrm{~h}$ & 0.14 & $1.30(0.67-2.49)$ & 0.437 & 0.09 & $1.91(0.99-3.69)$ & 0.055 \\
\hline$>24 \mathrm{~h}$ & 0.17 & $1.50(0.86-2.61)$ & 0.150 & 0.12 & $2.65(1.45-4.86)$ & 0.002 \\
\hline \multicolumn{7}{|l|}{ Time of contact } \\
\hline 4-8 pm on weekdays & 0.22 & 1 (reference) & & 0.11 & 1 (reference) & \\
\hline 8 pm-8 am on weekdays & 0.13 & $0.57(0.34-0.95)$ & 0.033 & 0.07 & $0.70(0.40-1.22)$ & 0.205 \\
\hline Weekends and holidays & 0.11 & $0.40(0.23-0.68)$ & 0.001 & 0.10 & $0.69(0.44-1.61)$ & 0.112 \\
\hline \multicolumn{7}{|l|}{ Geographical location } \\
\hline Urban & 0.14 & 1 (reference) & & 0.09 & 1 (reference) & \\
\hline Rural & 0.15 & $1.11(0.12-0.34)$ & 0.639 & 0.09 & $1.11(0.76-1.61)$ & 0.588 \\
\hline
\end{tabular}

${ }^{\mathrm{a}}$ Two and 19 in telephone consultations and face-to-face consultations, respectively, excluded from analysis due to missing responses

${ }^{\mathrm{b}}$ Adjusted for age groups, duration of symptoms and time of contact

Table 4 shows the 166 medically irrelevant contacts (assessed by the GPs to be inappropriately directed to $\mathrm{OOH}-\mathrm{PC}$ and by the parents concern be non-severe problems). For telephone consultations, these contacts were statistically significantly more often seen on weekday evenings compared to weekday nights (adj. PR: 0.57 (95\% CI: 0.34-0.95)) and weekends and holidays (adj. PR: 0.40 (95\% CI: 0.23-0.68)). For face-to-face contacts, a similar trend (although not statistically significant) was seen. There was a tendency that longer symptom duration was associated with assessment as medically irrelevant for OOH-PC. Age of child and geographical location were not significantly associated with assessment as medically irrelevant for $\mathrm{OOH}-\mathrm{PC}$.

\section{Discussion \\ Main results}

In $60 \%$ of telephone consultations and $40 \%$ of face-toface consultations, parents considered the health problem as non-severe. In one fifth of these, the GPs also considered the problem as unappropriate for $\mathrm{OOH}-\mathrm{PC}$. For telephone consultations, we found that contacts during 4-8 p.m. on weekdays was significantly associated with assessment as medically irrelevant for $\mathrm{OOH}-\mathrm{PC}$, that is, considered to be more appropriately directed to daytime care by GPs and health problem was considered non-severe by parents. In face-to-face consultations, symptom duration of more than $12 \mathrm{~h}$ was significantly associated with medical irrelevance for $\mathrm{OOH}-\mathrm{PC}$.

\section{Strengths and limitations}

Data originated from a large study on contacts to the $\mathrm{OOH}-\mathrm{PC}$ service (LV-KOS), which ensured high statistical precision. Furthermore, the participating GPs and the random inclusion of contacts have been demonstrated to be highly representative of all contacts to OOH-PC [8]. As patient contacts were randomly recruited through electronic pop-up questionnaires and the participation rate among GPs was high, the risk of selection bias was limited. Respondents and non-respondents did not differ significantly on the included variables, except that the GPs rated the medical relevance for OOH-PC somewhat lower for non-respondents. As a larger share of the medically irrelevant contacts are likely to be perceived as non-severe by parents, we may have underestimated the number of contacts with low parent-assessed severity; if this is the case, our results represent conservative estimates of the investigated association.

The short time period between contacting OOH-PC and receiving the questionnaire reduced the risk of recall bias in the parents. Still, we cannot entirely rule out the possibility of recall bias as the parents assessed the severity of the health problem several days after the contact. Their child may have 
recovered, and this may have affected their response and their assessment of the treatment received. This might result in an underestimation of the severity in retrospect among parents and an overestimation of the proportion of contacts assessed as non-severe.

The share of contacts assessed as unappropriate for $\mathrm{OOH}-\mathrm{PC}$ was similar for the two contact types. This may be surprising as the children seen in face-to-face consultations had already been triaged by a GP by telephone. However, the basis for the GP assessment of the medical appropriateness for $\mathrm{OOH}-\mathrm{PC}$ varies by type of contact as the triaging GP only had information from the telephone interview and needed a safety margin. Therefore, some of these cases may have been referred to a face-to-face consultation even though they turned out to be medically irrelevant for $\mathrm{OOH}-\mathrm{PC}$. Moreover, according to the Danish clinical guidelines, all children below the age of six months with fever should be seen in a face-to-face consultation.

It would have been relevant to include RFEs in the regression analyses in a study focusing on medical relevance. However, due to the large diversity in RFEs, the statistical precision would be reduced by including RFEs in the multivariate analyses.

\section{Comparison with existing literature}

Young children are more often sick than older children or adults $[14,15]$. Therefore, this patient group is more frequently seen in $\mathrm{OOH}-\mathrm{PC}$; this group accounts for about one fifth of all calls $[8,16]$. In accordance with other studies of children aged less than 5 years, we found fever, earache, coughing, breathing difficulties and vomiting the most common RFEs [12, 15, 17].

Our finding that many calls from parents to $\mathrm{OOH}-\mathrm{PC}$ concern health problems in children which are often considered medically inappropriate for OOH-PC by the GPs is in line with results from other studies in similar settings [4-6, 18]. In a Norwegian survey on the urgency of calls to OOH-PC, $84.4 \%$ of calls regarding children below ten years of age were considered to concern nonurgent health problems [6]. Similarly, $44.9 \%$ of all contacts regarding children below two years of age and $55.8 \%$ contacts regarding children above two years of age to the emergency department of a paediatric department in Belgium were considered to concern nonurgent health problems [18]. In addition, a study showed that the rate of telephone consultations was almost four times as high for Danish children than for Dutch children [3]. The organisation of health care in general, including $\mathrm{OOH}$ primary care, is rather similar in the two countries [1]. Therefore, this difference could indicate that more contacts in Denmark concern health issues that are considered medically irrelevant for $\mathrm{OOH}-\mathrm{PC}$.
Yet, previous studies indicate similar patterns of patient behaviour in the two countries [4].

We found several factors to be related to medical irrelevance for OOH-PC. The parents' motives for contacting the $\mathrm{OOH}-\mathrm{PC}$ have been investigated in several studies. Frequently mentioned motives were feelings of worry or fear, inadequateness to take care of their sick child, lack of control of their child's condition and need for medical information or symptom relief [12, 15, 19]. To increase the quality of care and the efficiency in $\mathrm{OOH}-\mathrm{PC}$, it may be best for parents to wait and present their child's health problem to the GP in the daytime. Moreover, the GP often knows the family beforehand and is more able to estimate the condition of the child using the already established relation with the parents. However, several studies indicate that this may not be possible in all cases as the psychosocial context of a child's illness and the feeling of worry are likely to overrule other more rational reflections on the most relevant behaviour and the best use of resources [20-22].

Decisions on calling for medical advice are influenced by an array of various elements. Besides the actual medical problem, the parents' knowledge and degree of feeling secure in managing their child's illness are the main drivers for the decision-making [12]. Moreover, sociodemographic factors have been found to be associated with patient behaviour [23, 24]. These would have been relevant to include in the analyses of present study, but such information was not available. Future studies focusing on children in the OOH-PC should be designed to address the potential association between parent behaviour and sociodemographic factors.

\section{Generalisability and implications for research and practice} As parents frequently worry when their child is ill, it is relevant to aim directly at this issue in future studies to gain more knowledge and to identify potential ways of redirecting calls to daytime care. This may especially be relevant if calls are related to structural factors, such as perceived inaccessibility to own GP in the daytime, which has been shown to be associated with increased use of acute care services $[25,26]$. The finding that most of the telephone consultations that were considered medically irrelevant for $\mathrm{OOH}-\mathrm{PC}$ were seen during the first opening hours of the OOH-PC services on weekdays supports that this could be an important structural issue. As parents considered their child's condition as non-severe in many cases, it would be relevant to examine more closely their motives for contacting the $\mathrm{OOH}$ $\mathrm{PC}$ anyway. More insight in the reasons for contacting $\mathrm{OOH}-\mathrm{PC}$ could provide input for better patient education and GP training. It would be particularly relevant to address the different elements that influence the motives 
for different help-seeking behaviour, such as individual sociodemographic factors and former experience with help-seeking. These components could be supplemented by exploring organizational factors related to the structure of the health care services, such as the accessibility to a GP within office hours.

\section{Conclusions}

In this study of contacts concerning health issues in young children under six years of age to $\mathrm{OOH}-\mathrm{PC}$ in Denmark, we found that fever, cough and ear pain were the most common RFEs. Parents assessed $60.7 \%$ of telephone consultations and $40.6 \%$ of face-to-face consultations to concern non-severe problems. GPs assessed that about $18 \%$ of contacts concerning children should have been directed to the daytime GP. Of these GP-assessed inappropriate contacts, parents considered the health problems as non-severe in $80 \%$ of the telephone consultations and in $50 \%$ of the face-to-face consultations. Contacts in the early evening on weekdays and contacts involving longer symptom duration $(>24 \mathrm{~h}$ ) were associated with medical irrelevance for $\mathrm{OOH}-\mathrm{PC}$. The results show varying perspectives between parents and GPs and confirm the challenge of defining the appropriate use of $\mathrm{OOH}-\mathrm{PC}$. Future studies focusing on parents' motives and behaviour would be recommendable to establish more evidence on factors related to medical relevance of calls to $\mathrm{OOH}-\mathrm{PC}$ in order to identify avoidable contacts.

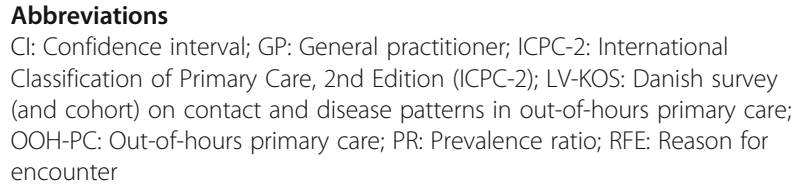
Classification of Primary Care, 2nd Edition (ICPC-2); LV-KOS: Danish survey (and cohort) on contact and disease patterns in out-of-hours primary care; $\mathrm{OOH}-\mathrm{PC}$ : Out-of-hours primary care; PR: Prevalence ratio; RFE: Reason for encounter

\section{Acknowledgements}

The authors would like to thank all the GPs who participated in this study.

\section{Funding}

This project was supported by the County of Aarhus, the Central Denmark Region, the Danish General Practice Fund and the Danish foundation Trygfonden. The financial support provided by these organisations partly covered the salaries of the researchers, the logistic expenses of the study (e.g. printing and postage of questionnaires), and the remuneration fees for participating GPs. The funding bodies were not involved in any part of the study nor in the writing of the manuscript.

\section{Availability of data and materials}

The dataset used and analysed during the current study is available from the corresponding author on reasonable request.

\section{Authors' contributions}

GM designed the study and contributed substantially to the acquisition, analysis and interpretation of data. GM made the first draft and the subsequent revisions of the manuscript and approved the final version. $\mathrm{LH}$ contributed substantially to defining the aim of the article and interpreting the data and participated actively in the writing and critical revision of the manuscript. Furthermore, $\mathrm{LH}$ approved the final version of the manuscript. $\mathrm{AO}$ contributed substantially to the literature search related to the study, participated in the writing and revision of the manuscript and approved the final version of the manuscript. MBC contributed substantially to the design of the LV-KOS study, participated in the writing and revision of the manuscript and approved the final version of the manuscript. PV contributed substantially to the design of the study and the interpretation of data and participated in the writing and critical revision of the manuscript and approved the final version of the manuscript. All authors read and approved the final manuscript.

\section{Ethics approval and consent to participate}

The project was approved by the Danish Data Protection Agency (R. no. 2009-41-4069) and by the Danish Health and Medicines Authority (R. no. 7-604-04-2/122/EHE). According to Danish law, approval from the health research ethics committee system was not needed (http://www.nvk.dk/). A specific written consent was not obtained, as the participants, GPs and patients, were informed that accepting to fill out and return questionnaires meant giving consent. The participating GPs received a fee that was dependent on the number of registered contacts.

Consent for publication

Not applicable.

\section{Competing interests}

The authors declare that they have no competing interests.

\section{Publisher's Note}

Springer Nature remains neutral with regard to jurisdictional claims in published maps and institutional affiliations.

Received: 19 July 2017 Accepted: 18 December 2017

Published online: 28 December 2017

\section{References}

1. Grol R, Giesen P, van Uden C. After-hours care in the United Kingdom, Denmark, and the Netherlands: new models. Health Aff (Millwood). 2006; 25(6):1733-7.

2. Huibers L, Giesen P, Wensing M, Grol R. Out-of-hours care in western countries: assessment of different organizational models. BMC Health Serv Res. 2009:9:105-6963-9-105.

3. Huibers L, Moth G, Andersen M, van Grunsven P, Giesen P, Christensen MB, et al. Consumption in out-of-hours health care: Danes double Dutch? Scand J Prim Health Care. 2014;32(1):44-50.

4. Keizer E, Smits M, Peters Y, Huibers L, Giesen P, Wensing M. Contacts with out-of-hours primary care for nonurgent problems: patients' beliefs or deficiencies in healthcare? BMC Fam Pract. 2015;16(1):157-015-0376-9.

5. Vedovetto A, Soriani N, Merlo E, Gregori D. The burden of inappropriate emergency department pediatric visits: why Italy needs an urgent reform. Health Serv Res. 2014;49(4):1290-305.

6. Hansen EH, Zakariassen E, Hunskaar S. Sentinel monitoring of activity of outof-hours services in Norway in 2007: an observational study. BMC Health Serv Res. 2009;9:123-6963-9-123.

7. Iliffe S, Haug U. Out of hours work in general practice. BMJ. 1991;302(6792): 1584-6.

8. Flarup L, Moth G, Christensen MB, Vestergaard M, Olesen F, Vedsted P. A feasible method to study the Danish out-of-hours primary care service. Dan Med J. 2014;61(5):A4847.

9. Huibers LA, Moth G, Bondevik GT, Kersnik J, Huber CA, Christensen MB, et al Diagnostic scope in out-of-hours primary care services in eight European countries: an observational study. BMC Fam Pract 2011;12:30-2296-12-30.

10. Zwaanswijk M, Nielen MM, Hek K, Verheij RA. Factors associated with variation in urgency of primary out-of-hours contacts in the Netherlands: a cross-sectional study. BMJ Open. 2015;5(10):e008421-2015-008421.

11. Moth G, Huibers L, Christensen MB, Vedsted P. Out-of-hours primary care: a population-based study of the diagnostic scope of telephone contacts. Fam Pract. 2016:33(5):504-9.

12. Kallestrup P, Bro F. Parents' beliefs and expectations when presenting with a febrile child at an out-of-hours general practice clinic. Br J Gen Pract. 2003; 53(486):43-4.

13. WONCA. International classification of primary care. ICPC-2-R. Second ed. New York: Oxford University Press; 2005.

14. Bruijnzeels MA, Foets M, van der Wouden JC, van den Heuvel WJ, Prins A. Everyday symptoms in childhood: occurrence and general practitioner consultation rates. Br J Gen Pract. 1998;48(426):880-4. 
15. Ertmann RK, Siersma V, Reventlow S, Soderstrom M. Infants' symptoms of illness assessed by parents: impact and implications. Scand J Prim Health Care. 2011;29(2):67-74.

16. Moth G, Flarup L, Christensen M, Olesen F, Vedsted P. Reasons for encounter and disease patterns in the Danish out-of-hours primary care service. LV-KOS (in Danish). 1st ed. Aarhus: The Research Unit for General Practice, Aarhus University; 2012.

17. Kai J. What worries parents when their preschool children are acutely ill, and why: a qualitative study. BMJ. 1996;313(7063):983-6.

18. Benahmed N, Laokri S, Zhang WH, Verhaeghe N, Trybou J, Cohen L, et al. Determinants of nonurgent use of the emergency department for pediatric patients in 12 hospitals in Belgium. Eur J Pediatr. 2012;171(12):1829-37.

19. Shipman C, Dale J. Using and providing out-of-hours services: can patients and GPs agree? Health Soc Care Community. 1999;7(4):266-75.

20. Richtsmeier AJ, Hatcher JW. Parental anxiety and minor illness. J Dev Behav Pediatr. 1994;15(1):14-9.

21. Hopton J, Hogg R, McKee I. Patients' accounts of calling the doctor out of hours: qualitative study in one general practice. BMJ. 1996;313(7063):991-4.

22. Bernthal EM, Lathlean J, Gobbi M, Simpson RG. Mothers' decision-making during times of stress as a lone parent: a qualitative study. J R Army Med Corps. 2015;161(Suppl 1):i26-33.

23. Buja A, Toffanin R, Rigon S, Lion C, Sandona P, Carraro D, et al. What determines frequent attendance at out-of-hours primary care services? Eur J Pub Health. 2015;25(4):563-8

24. Jansen T, Zwaanswijk M, Hek K, de Bakker D. To what extent does sociodemographic composition of the neighbourhood explain regional differences in demand of primary out-of-hours care: a multilevel study. BMC Fam Pract 2015;16:54-015-0275-0.

25. Smits M, Peters Y, Broers S, Keizer E, Wensing M, Giesen P. Association between general practice characteristics and use of out-of-hours GP cooperatives. BMC Fam Pract 2015;16:52-015-0266-1.

26. Zhou Y, Abel G, Warren F, Roland M, Campbell J, Lyratzopoulos G. Do difficulties in accessing in-hours primary care predict higher use of out-ofhours GP services? Evidence from an English National Patient Survey. Emerg Med J. 2015:32(5):373-8.

\section{Submit your next manuscript to BioMed Central and we will help you at every step:}

- We accept pre-submission inquiries

- Our selector tool helps you to find the most relevant journal

- We provide round the clock customer support

- Convenient online submission

- Thorough peer review

- Inclusion in PubMed and all major indexing services

- Maximum visibility for your research

Submit your manuscript at www.biomedcentral.com/submit

) Biomed Central 